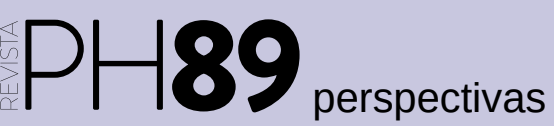

a debate Patrimonio, turismo y género. Estrategias para integrar la perspectiva de género en el patrimonio histórico

| coordinan Margarita M. Birriel Salcedo, Carmen Rísquez Cuenca

\title{
Restituyendo la memoria de las mujeres a través del patrimonio social urbano
}

\author{
Nuria Álvarez Lombardero | Architectural Association School of Architecture \\ URL de la contribución <www.iaph.es/revistaph/index.php/revistaph/article/view/3724>
}

El patrimonio se ha considerado tradicionalmente como aquello que es herencia "común" de una colectividad, organizado como el conjunto de bienes y medios materiales que han de ser preservados. Hasta el momento los debates sobre el entorno construido y lo determinable como patrimonial o culturalmente valorable se han dado sin tener en cuenta los valores propios de aquellos grupos sociales considerados como minoritarios. Hasta ahora las instituciones no han considerado seriamente aspectos sociales y políticos a la hora de definir valores patrimoniales relevantes, perjudicando a aquellas minorías que han dado importancia al sentido de lugar en la ciudad como parte de su lucha por ser visibles. Lo que se plantea en este artículo es la posibilidad de que el patrimonio también pueda considerar "otros" criterios, tratando de construir y reconocer un lugar en la ciudad a aquellos que en un cierto momento de la historia fueron sustraídos de él.

El pasado tiene distinto significado para los individuos y grupos sociales que forman una misma ciudad. Las grandes urbes están formadas por diferentes grupos de ciudadanos con valores culturales o socio-históricos divergentes que constantemente están llevando a cabo de manera espontánea sus propios proyectos para representar y contar la historia de su comunidad en los espacios públicos. Los estudios elaborados por la historiadora Gail Lee Dubrow $(1991 ; 2003)$ y la urbanista Dolores Hayden (1995), que estudian las experiencias recordadas por mujeres y ciudadanos pertenecientes a las minorías étnicas en el espacio público, responden a esta multiplicidad de facetas de la ciudad y demuestran que existen estas reivindicaciones culturales por parte de estos grupos sociales olvidados que contribuyen a las políticas de construcción de lugar ${ }^{1}$.

El poder de los espacios urbanos ordinarios, que sustentan la memoria pública de los ciudadanos en forma de "territorio común", aún se mantiene sin ser explotado por estas historias particulares. Bajo esta nueva concepción, se plantearían dos retos fundamentales a la hora de hacer patrimonio: por un lado, encontrar el modo de definir tales valores en la esfera pública a través de recuperar esas historias olvidadas y, por otro, encauzar la mediación siempre comprometida entre pasado y futuro, que nos llevará en muchos casos a interpretar edificios de naturaleza arquitectónica modesta, pero con un gran valor cultural para la comunidad.

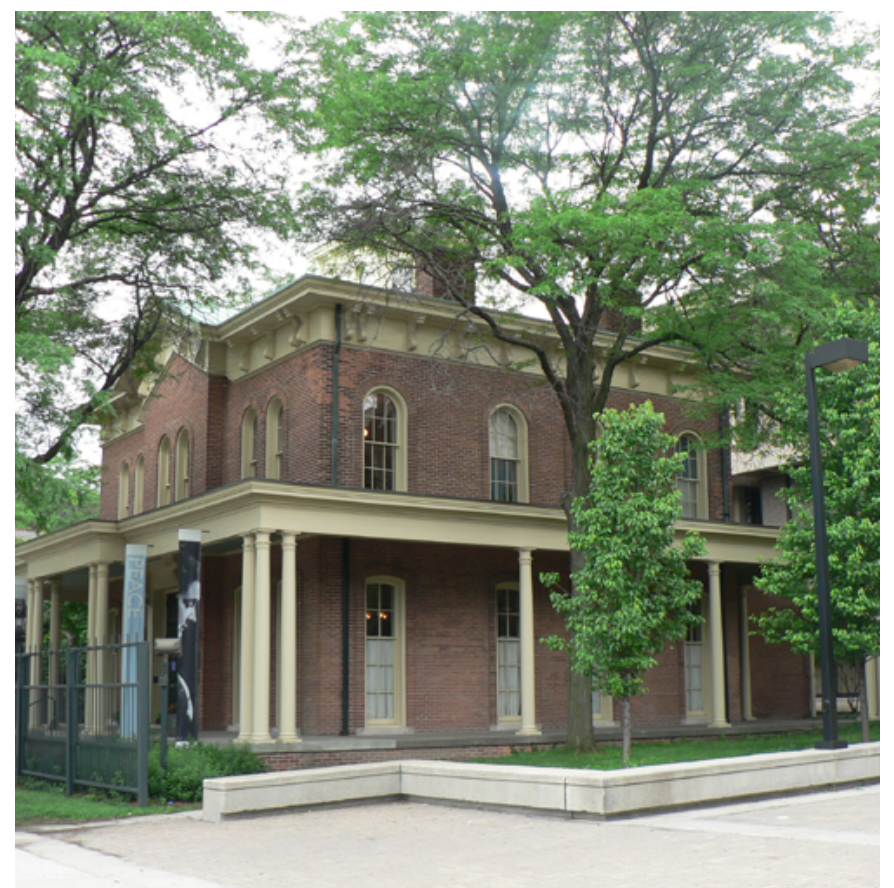

Museo Hull House en Chicago que recoge la memoria del trabajo realizado por su fundadora Jane Addams y sus colaboradoras residentes, quienes se encargaban de dar oportunidades educacionales y sociales a los vecinos del barrio colindante, así como de apoyar las reformas políticas municipales, estatales o federales en temas como el sufragio, la explotación de menores o la política de emigración | foto Nuria Álvarez Lombardero, 2007 
En este sentido las mujeres, que han ido situándose históricamente en los espacios urbanos, públicos o semi-públicos, pensados a priori por y para el hombre, han mantenido una lucha constante por recuperar y mantener un lugar propio en la ciudad que les permitiera desligarse de las ataduras del espacio doméstico. Desde finales del siglo XIX las mujeres han ido redefiniendo los espacios urbanos existentes a través de cartografías propias, trazadas virtualmente a través de sus desplazamientos por la ciudad, que unían aquellos lugares que consideraban adecuados para sí mismas, generando así sus lugares de acción (ALVAREZ LOMBARDERO, 2014). Como comenta el geógrafo Yi Fu Tuan (1997: 12-13): "El lugar es dado por la facultad de movimiento. Los movimientos son a menudo dirigidos hacia, o repelidos por los objetos o espacios. De este modo el lugar puede ser variablemente experimentado como situación relativa entre objetos o espacios". Para explicar esta teoría Tuan utiliza el ejemplo de las mujeres esquimales de Aivilik, que definían su espacio mediante la situación y la distancia de puntos significativos desde un punto base, mientras que los hombres de la misma tribu basaban su sentido del espacio mediante la línea costera. Hombres y mujeres han tenido distintas maneras de "colonizar" el territorio urbano debido a sus distintas situaciones, y por tanto, generando una escala de valores urbanos diferentes.

De esta manera se propone la puesta en valor una nueva política de construcción del lugar, redefiniendo la experiencia establecida culturalmente por las mujeres y haciendo visibles algunas de sus partes olvidadas pues, como indica Dolores Hayden: "La identidad está íntimamente atada a la memoria: tanto por nuestra memoria personal como por las memorias colectivas o sociales interconectadas con las historias de nuestras familias, vecinos, compañeros de trabajo, y comunidades étnicas. El paisaje urbano es el almacén para estas memorias sociales, porque elementos naturales como colinas y puertos, así como calles, edificios y patrones de asentamiento, enmarcan las vidas de mucha gente y a menudo sobreviven muchas vidas" (HAYDEN, 1995: 9). Por tanto es a través de dar memoria a las acciones de las mujeres en el pasado, en el espacio público, como se está otorgando a las mujeres identidad y valor en la sociedad. El patrimonio cultural debe redefinir sus herramientas para poner en valor las acciones y movimientos de las mujeres en la historia de la ciudad, con estrategias que difieran de las actuales dentro de los cánones existentes.

\section{NOTA}

1. El trabajo de Dolores Hayden, que propone el tener en cuenta no sólo los grupos de poder sino el conjunto de los diferentes grupos sociales, se enmarca en una investigación aun mayor elaborada por la historiadora norteamericana Gail Lee Dubrow sobre la restauración de la historia de la mujer a través del patrimonio, pues lugares históricos y edificios juegan un papel primordial en la educación de la sociedad sobre el pasado de un país.

\section{BIBLIOGRAFÍA}

- Álvarez lombardero, N. (2014) Mujeres en la ciudad: Rompiendo los límites del Planeamiento Urbano Moderno. Tesis doctoral inédita, Universidad de Sevilla, 2014

- HAYDEN, D. (1995) The Power of Place: Urban landscapes as public history. Cambridge, Mass.: The MIT Press, 1995

- DUBROW, G. L. (1991) Claiming Public Space for Women's History in Boston: A proposal for Preservation, Public Art, and Public Historical Interpretation. Frontiers: A Journal of Women's studies, 13, 1, 1991, pp. 111-48

- DUBROW, G. L.; GOODMAN, J. (eds.) (2003) Restoring women's history through historic preservation. Baltimore: Johns Hopkins University Press, 2003

- TUAN, Y. F. (1997) Space and Place: The perspective of experience. Minneapolis, Minn: University of Minnesota Press, 1977 